\title{
Commentary Improved cardiac arrest outcomes: as time goes by?
} Peter T Morley

Intensive Care Unit, Royal Melbourne Hospital, Grattan Street, Parkville, Victoria, Australia 3050

Corresponding author: Peter T Morley, peter.morley@mh.org.au

Published: 8 May 2007

This article is online at http://ccforum.com/content/11/3/130

(c) 2007 BioMed Central Ltd

See related research by Mally et al., http://ccforum.com/content/11/2/R39
Critical Care 2007, 11:130 (doi:10.1186/cc5784)

\begin{abstract}
In a recent issue of Critical Care, Mally and colleagues reported outcomes from an observational study of out-of-hospital cardiac arrests in Slovenia. Multivariable analysis identified independent predictors for hospital discharge, including higher end-tidal carbon dioxide $\left(\mathrm{ETCO}_{2}\right)$ levels, higher mean arterial pressure (MAP) and the recency (years) of the arrest. $\mathrm{ETCO}_{2}$ has been previously demonstrated to correlate with cardiac index, and predict successful resuscitation. Initial $\mathrm{ETCO}_{2}$ reflects the initial adequacy of resuscitation, and the $\mathrm{ETCO}_{2}$ on admission to hospital reflects a number of factors, including the adequacy of ventilation. During resuscitation, coronary perfusion pressure appears important for survival, but there are limited human data to guide hemodynamic management after cardiac arrest. A higher blood pressure could represent more vasoconstriction, less vasodilation, avoidance of hyperventilation, or a better cardiac output. Improved hospital discharge was also observed during the later years of the study. During this period a number of factors could have contributed to the improved outcome. These include new guidelines, the awareness of the importance of good CPR (including avoidance of hyperventilation), and better post-resuscitation care (including therapeutic hypothermia). It is hard to unravel the actual contribution of these factors to the final outcome, but the authors should be commended for their excellent overall results, and their thought provoking manuscript.
\end{abstract}

The ultimate goal of cardiac arrest research is to search for potential improvements in care that translate into better neurological outcome. Ideally with these improvements we also search for a plausible mechanism. In Critical Care, the authors of an observational study of out-of-hospital cardiac arrests [1] reported not only an improvement in neurological outcome, but also a number of possible mechanisms.

Mally and colleagues [1] reviewed the outcomes of over 600 out-of-hospital cardiac arrests managed by a physician-based pre-hospital team in Maribor (Slovenia) over a six year period (between January 2000 and April 2006). They report excellent overall outcomes (hospital discharge rates $>20 \%$ for out-of-hospital cardiac arrests who were administered a vasopressor). They also report a significantly increased number of neurologically intact survivors (defined as a Cerebral Performance Category 1 or 2 ) in the group that received vasopressin as part of their resuscitation (26/146, $17.8 \%)$, compared with the group that received only epinephrine (47/452, 10.4\%; odds ratio 1.87; 95\% confidence interval 1.11 to 3.14 ). These results were derived, however, using only a univariate analysis. The authors did go on to evaluate multiple factors that could have been responsible for these improvements, and using a multivariable analysis identified a number of independent predictors for hospital discharge. These were: a witnessed arrest; bystander CPR; higher end-tidal carbon dioxide $\left(\mathrm{ETCO}_{2}\right.$ : 'initial', 'average' and 'final') values; shorter time to arrival of the pre-hospital medical team; higher mean arterial pressure (MAP) on admission to hospital; the presence of a shockable rhythm; and a more recent arrest (second three years of study compared with first three years of study) [1]. Most of these predictors have been consistently observed in other studies. Three specific factors are, however, worth additional consideration: $\mathrm{ETCO}_{2}, \mathrm{MAP}$ and the year of arrest.

$\mathrm{ETCO}_{2}$ levels have been demonstrated in animal models to fall immediately at the onset of cardiac arrest, increase immediately with chest compressions, provide a linear correlation with cardiac index, predict successful resuscitation (when able to maintain a level exceeding 25\% of baseline) and allow detection of return of spontaneous circulation when a sudden increase in the $\mathrm{ETCO}_{2}$ level occurred [2]. Its role (including its prognostic value) is further supported by recent studies in animals and cardiac arrests in the emergency department [3]. The same team from Slovenia have also reported the predictive outcomes of $\mathrm{ETCO}_{2}$ in a subset of Mally's patients (from January 2001 to December 2004 [4]). Initial $\mathrm{ETCO}_{2}$ is likely to reflect the initial adequacy of resuscitation (higher value, higher cardiac output). Final $\mathrm{ETCO}_{2}$ (value on admission to hospital) reflects a number of 
factors, but given a persistent return of spontaneous circulation it is likely to be indicative of the adequacy of ventilation (higher value, lower minute ventilation; or lower arterial-ETCO 2 gradient [5]).

Invasive pressure monitoring is not usually available during resuscitation, and in this study a non-invasive monitor estimated MAP. Coronary perfusion pressure (incorporating diastolic blood pressure) during resuscitation has been demonstrated as important for survival, and animal data have supported an early period of hypertension. There are, however, limited human data to guide hemodynamic management after cardiac arrest. Reported successful blood pressure goals have varied from a period of relative hypertension (MAP 90 to $100 \mathrm{mmHg}$ ), to more standard goals (MAP >65 to $70 \mathrm{mmHg}$ [6]). In the current observational study [1], it is impossible to tell whether the observed higher blood pressure was a reflection of more vasoconstriction, less vasodilation (for example, sedation), avoidance of hyperventilation, or a better cardiac output.

The final and most interesting observation is the improved hospital discharge seen in the period of November 2003 through April 2006, compared with January 2000 through November 2003 [1]. Over this six year period, several factors could have impacted on outcome; these include advances in guidelines, improved quality of CPR and better postresuscitation management. Since January 2000, the International Guidelines 2000 [7], the 2005 Consensus on Science of the International Liaison Committee on Resuscitation [8], and the 2005 European Resuscitation Council guidelines [9] have all been published and could have altered management significantly. A number of articles confirming the importance of good CPR have been published. These include the adverse effects of interruptions to CPR [10], the importance of rate [11] and depth [10] of CPR, the potential value of CPR before defibrillation [12], and the adverse effects of hyperventilation [8,13]. Good CPR has also been associated with increased efficacy of vasoconstrictor drugs [14]. The most important improvement in post-resuscitation management probably relates to induced hypothermia [15], but other factors that may improve survival include glucose control, normoventilation, hemodynamic control and percutaneous coronary interventions [6].

This study [1] has all the inherent problems associated with observational studies, but despite these limitations it raises a number of interesting issues. It re-emphasizes the traditional predictive variables, the importance of monitoring $\mathrm{ETCO}_{2}$ and maintaining blood pressure, and reminds us of the complex nature of advancing time.

\section{Competing interests}

The authors declare that they have no competing interests.

\section{References}

1. Mally S, Jelatancev A, Grmec S: Effects of epinephrine and vasopressin on end-tidal carbon dioxide tension and mean arterial blood pressure in out-of-hospital cardiopulmonary resuscitation: an observational study. Crit Care 2007, 11:R39.

2. Gudipati C, Weil M, Bisera J, Deshmukh H, Rackow E: Expired carbon dioxide: a noninvasive monitor of cardiopulmonary resuscitation. Circulation 1988, 77:234-239.

3. Salen P, O'Connor R, Sierzenski P, Passarello B, Pancu D Melanson S, Arcona S, Reed J, Heller M: Can cardiac sonography and capnography be used independently and in combination to predict resuscitation outcomes? Acad Emerg Med 2001, 8:610-615.

4. Grmec S, Krizmaric M, Mally S, Kozelj A, Spindler M, Lesnik B: Utstein style analysis of out-of-hospital cardiac arrest Bystander CPR and end expired carbon dioxide. Resuscitation 2007, 72:404-414.

5. Moon SW, Lee SW, Choi SH, Hong YS, Kim SJ, Kim NH: Arterial minus end-tidal $\mathrm{CO} 2$ as a prognostic factor of hospital survival in patients resuscitated from cardiac arrest. Resuscitation 2007, 72:219-225.

6. Sunde K, Pytte M, Jacobsen D, Mangschau A, Jensen LP, Smedsrud C, Draegni T, Steen PA: Implementation of a standardised treatment protocol for post resuscitation care after out-ofhospital cardiac arrest. Resuscitation 2007, 73:29-39.

7. The American Heart Association in collaboration with the International Liaison Committee on Resuscitation (ILCOR): Guidelines 2000 for cardiopulmonary resuscitation and emergency cardiovascular care. Circulation 2000, 102(suppl I):I:1-I:403.

8. Proceedings of the 2005 International Consensus on Cardiopulmonary Resuscitation and Emergency Cardiovascular Care Science with Treatment Recommendations. Resuscitation 2005, 67:157-341.

9. European Resuscitation Council guidelines for resuscitation 2005. Resuscitation 2005, 67(Suppl 1):S1-189.

10. Edelson DP, Abella BS, Kramer-Johansen J, Wik L, Myklebust H, Barry AM, Merchant RM, Hoek TL, Steen PA, Becker LB: Effects of compression depth and pre-shock pauses predict defibrillation failure during cardiac arrest. Resuscitation 2006, 71:137145.

11. Abella BS, Sandbo N, Vassilatos $P$, Alvarado JP, O'Hearn N, Wigder HN, Hoffman P, Tynus K, Vanden Hoek TL, Becker LB: Chest compression rates during cardiopulmonary resuscitation are suboptimal: a prospective study during in-hospital cardiac arrest. Circulation 2005, 111:428-434.

12. Wik L, Hansen TB, Fylling F, Steen T, Vaagenes $P$, Auestad BH, Steen PA: Delaying defibrillation to give basic cardiopulmonary resuscitation to patients with out-of-hospital ventricular fibrillation: a randomized trial. JAMA 2003, 289:1389-1395.

13. Aufderheide TP: The problem with and benefit of ventilations: should our approach be the same in cardiac and respiratory arrest? Curr Opin Crit Care 2006, 12:207-212.

14. Pytte M, Kramer-Johansen J, Eilevstjonn J, Eriksen M, Stromme TA, Godang K, Wik L, Steen PA, Sunde K: Haemodynamic effects of adrenaline (epinephrine) depend on chest compression quality during cardiopulmonary resuscitation in pigs. Resuscitation 2006, 71:369-378.

15. Nolan JP, Morley PT, Vanden Hoek TL, Hickey RW, Kloeck WG, Billi J, Bottiger BW, Okada K, Reyes C, Shuster M, et al.: Therapeutic hypothermia after cardiac arrest: an advisory statement by the advanced life support task force of the International Liaison Committee on Resuscitation. Circulation 2003, 108:118-121. 